\title{
Środowisko sedymentacji i domniemane źródło materiału detrytycznego w górnokredowej formacji red-bed Ashua (Peru)
}

\author{
Andrzej Paulo ${ }^{1}$, Justyna Ciesielczuk², Grzegorz Racki², Jerzy Żaba², Krzysztof Gaidzik²
}

\begin{abstract}
Depositional environment and probable source of detritus in the Upper Cretaceous red-bed Ashua Formation (Peru). Prz. Geol., 67: 189-191; doi: 10.7306/2019.17

A b s tr a c t. Ashua Formation was deposited in Coniacian-Early Santonian time near shore of a shallow sea and in a plethora of continental arid environments. Its main component is fine-grained siliciclastic material forming lithic and subordinate arkosic graywackes. Limestones are frequent in the lower member, and in the upper one gypsum and halite are present. Based on sedimentary textures and detailed petrographic studies, nine general microfacies were identified: shallow sea, beach, brackisch and mudflats, lagoon, sabkha and playa, deltaic, alluvial, mud flows, dunes at shoreline of an agitated water basin. The present authors suggest that the main source of detritus was pyroclastic deposits. They probably belong to the heavily eroded Lower Cretaceous Matalaque Formation.
\end{abstract}

Keywords: Ashua Formation, Late Cretaceous, Peru, siliciclastic deposits, pyroclastic source

Od 2006 r. Polska Wyprawa Naukowa do Peru(PWNP) prowadzi badania geologiczne w rejonie Kanionu Colca i Doliny Wulkanów. Zmierzają one do ochrony obszaru o wybitnych walorach przyrody nieożywionej, odwiedzanego przez setki tysięcy turystów. Wstępnym krokiem, wyprzedzającym decyzję o zasięgu ochrony i jej formach, jest rozpoznanie formacji skalnych, genezy form morfologicznych, tektoniki, wulkanizmu, przeobrażeń endoi egzogenicznych itp. oraz wytypowanie stanowisk dokumentacyjnych. Dorobek PWNP jest prezentowany m.in. na stronie internetowej http://home.agh.edu.pl/ pwnp, a bieżące postępy były relacjonowane m.in. w Kwartalniku AGH Geologia (2008) i Przegladzie Geologicznym (2011/1, 2012/12 i 2017/11/3).

Celem artykułu jest charakterystyka głównego typu osadów górnokredowej formacji Ashua, jednej z najsłabiej poznanych, i próba określenia źródła materiału detrytycznego oraz środowiska transportu i depozycji. Formacja ta zawiera kopaliny: sól kamienną i gips, a także skupienia minerałów miedzi i zeolity. W Boliwii równowiekowe formacje o podobnej litologii obfitują w ślady gadów lub tanatocenozy ich szkieletów. Zarówno kopaliny, jak i skamieliny zwiększają potencjał atrakcyjności tej formacji, a skład mineralny i podatność na wietrzenie wpływają na jej właściwości mechaniczne.

\section{CHARAKTERYSTYKA FORMACJI ASHUA}

Formacja Ashua ma lokalny zasięg, ograniczony do południowego Peru (ryc. 1). Początkowo została opisana na południe od Huambo, na obszarze o długości $28 \mathrm{~km}$ i szerokości $20 \mathrm{~km}$ (Caldas, 1993), a następnie w izolowanych, dystalnych wystapieniach na skraju pokrywy kenozoicznej i uznana za odpowiednik gorzej zdefiniowanych warstw Chilcane, Querque i Seraj. Według obecnego rozpoznania przez geologów peruwiańskich odsłania się ona z przerwami w wąskim pasie o długości ok. $230 \mathrm{~km}$ od
Saporo przez okolice Ashua i Yura po Carumas (Caldas i in., 2002, Demouy, 2012).

Formacja Ashua została zdefiniowana przez Cruz (2002) w kategoriach stratygrafii sekwencyjnej wyłącznie na podstawie obserwacji terenowych i kilku próbek wapieni z fauna. W profilu stratygraficznym leży niezgodnie na udokumentowanej paleontologicznie formacji morskiej Arcurquina lub jej redeponowanym (olistolitowym) ogniwie Ayabacas (koniak), a pod kontynentalną formacją molasową Huanca (eocen) i jest przebita przez paleogeńską (?) intruzję dacytową. Ma miąższość 300-350 m. Jest dwudzielna. Dolne ogniwo zawiera liczne wkładki wapieni z fauną santonu (Vicente, 1981), górne zaczyna się zlepieńcem polimiktycznym i składa się niemal wyłącznie z naprzemianległych warstw mułowców i piaskowców z wkładkami gipsu i soli kamiennej.

Badania uczestników PWNP bazują na ponownym profilowaniu i opróbowaniu w terenie, obserwacjach w mikroskopie polaryzacyjnym i SEM, wspartych doraźnie identyfikacją rentgenograficzną i szczegółowymi analizami termoluminescencyjnymi.

Wyniki analizy paleogeograficznej i facjalnej potwierdzają główną opinię, że dolne ogniwo formacji Ashua osadziło się przy brzegu morza epikontynentalnego, należącego do szelfu zachodniego Peru, który był oddzielony od Pacyfiku proto-Kordylierą Nadbrzeżną (lub łukiem wyspowym), a w górnej kredzie również od basenu załukowego wschodniego Peru i Boliwii, piętrzącym się wyniesieniem Marañón. Górne ogniwo Ashua powstawało niemal wyłącznie w środowisku kontynentalnym.

Analizy petrograficzne sugerują następujące środowiska depozycji:

1) płytkomorskie - sparytowe i mikrytowe wapienie bioklastyczne obfitujące w szczątki liliowców, jeżowców, małży, ślimaków, mszywiołów, małżoraczków, otwornic

\footnotetext{
${ }^{1}$ Wydział Geologii, Geofizyki i Ochrony Środowiska, Akademia Górniczo-Hutnicza im. S. Staszica, al. Mickiewicza 30, 30-059 Kraków; andrzej.paulo@interia.pl

${ }^{2}$ Wydział Nauk o Ziemi, Uniwersytet Śląski, ul. Będzińska 60, 41-200 Sosnowiec; justyna.ciesielczuk@us.edu.pl; grzegorz.racki@us.edu.pl; jerzy.zaba@us.edu.pl; krzysztof.gaidzik@us.edu.pl
} 


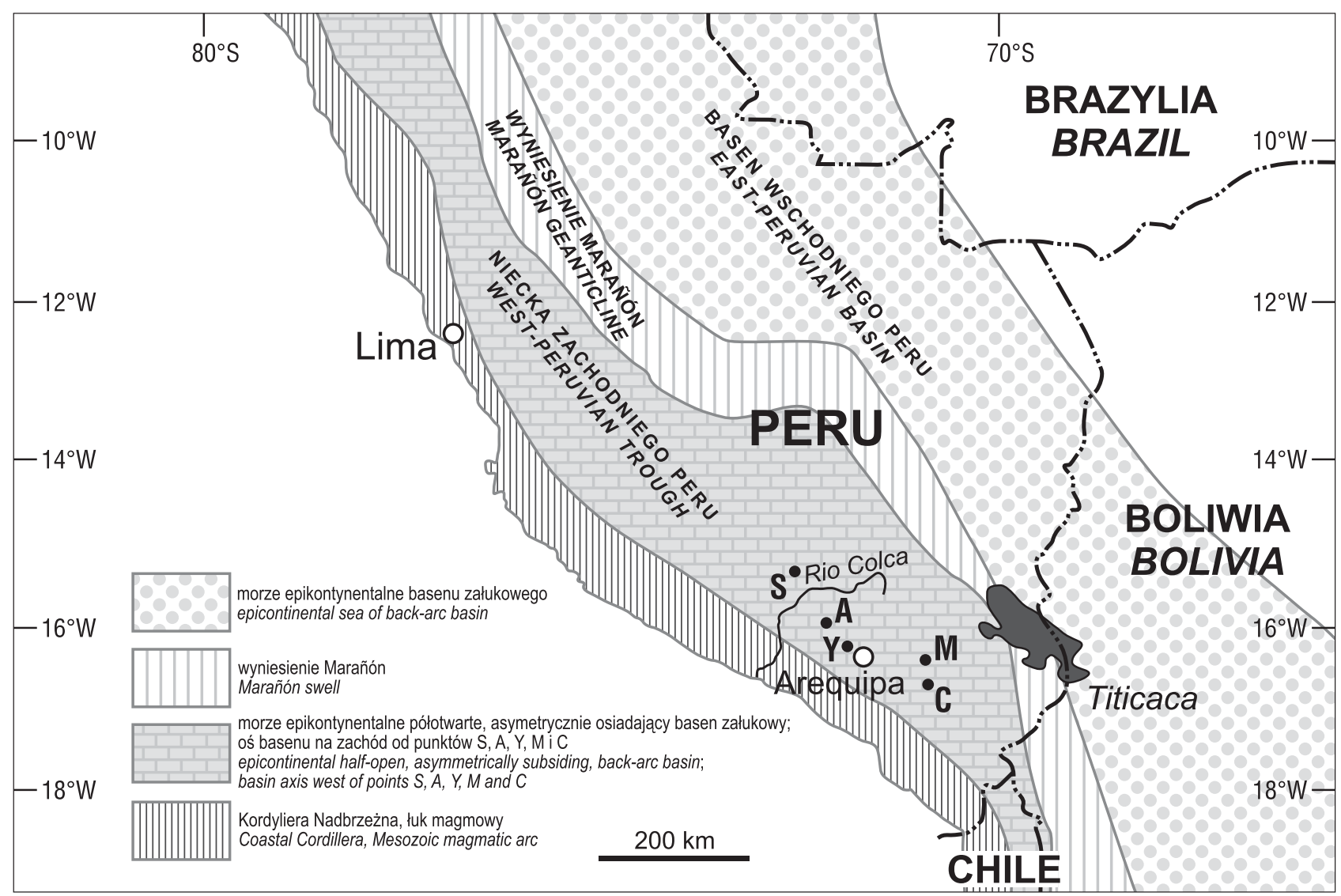

Ryc. 1. Szkic paleogeograficzny środkowych Andów w kredzie. M - stratotyp formacji Matalaque. Odsłonięcia formacji Ashua: A - Ashua, C - Carumas, S - Saporo, Y - Chilcane k. Yura

Fig. 1. Sketch of paleogeography of the Central Andes in Cretaceous time. $\mathbf{M}$ - stratotype of Matalaque Formation. Points of the Ashua Fm. denote regional outcrops: A - Ashua, C - Carumas, S-Saporo, Y - Chilcane near the Yura

oraz ryb, ze skałotwórczymi zielonymi glonami Dasycladaceae i ooidami;

2) plażowe i przybrzeżnomorskie - wapienie detrytyczne $\mathrm{z}$ fragmentami mat glonowych, w tym osady sztormowe;

3) brakiczne, równi mułowych i nadmorskich salin osady węglanowe (mikryty) z domieszką mułu silikoklastycznego, ze śladami żerowania i fauną ograniczoną do małżoraczków;

4) lagunowe - margle kalcytowo-dolomitowo-ilaste ze skorodowanym detrytusem silikoklastów, bioklastami (m. in. małżoraczków) i rozproszoną materią węglistą, a także częściowo zlimonityzowanymi siarczkami $\mathrm{Fe}$ i $\mathrm{Cu}$ oraz neomorficznym barytem;

5) sabkha przybrzeżna i wysychające zbiorniki typu playa - niewysortowane osady mułowcowe z domieszką piasku o spoiwie gipsowym i dolomitowym, osady piasku węglanowego z ripplemarkami;

6) deltowe - osady silikoklastyczne piaskowcowo-mułowcowe z bioklastami kalcytowymi, margle seladonitowo-kalcytowe, wapienie piaszczyste;

7) rzek okresowych, powodziowe (i estuariów?) - osady silikoklastyczne frakcji piaszczysto-mułowej, podrzędnie iłowej, facji Fm, Sm, rzadziej Fl, Fm, St, Sl, Sh (Miall, 1996);

8) spływy błotne - różnoziarniste (do $20 \mathrm{~cm}$ ) zlepieńce polimiktyczne $\mathrm{z}$ dominującym spoiwem mułowym, często porowatym;

9) wydmy na brzegu zbiornika wodnego - dobrze wysortowane piaskowce o warstwowaniu przekatnym klinowym i tabularnym, przechodzące w piaskowce $\mathrm{z}$ laminami minerałów ciężkich.

Warstwy silikoklastyczne tworzą około $80 \%$ objętości formacji Ashua. Mułowce są na ogół ciemnoczerwone, piaskowce różowe, rzadziej jasnoszare, pstre lub zielone, a wapienie - szare, ochrowe, a wyjątkowo ciemnoszare, wietrzejące na brązowo. Wspólną cechą szkieletu skał silikoklastycznych jest słaby stopień obtoczenia, zwłaszcza frakcji mułowej i drobnego piasku, a w niektórych warstwach nawet obecność kanciastych, sierpowatych ziaren, charakterystycznych dla szkliwa. Mają spoiwo podstawowe typu matrix, sąźle wysortowane. Kontrastowo, w dużych klastach zlepieńca występują głównie porfirowe skały wulkaniczne i piaskowce kwarcytowe. Te ostatnie wykazuja dobre wysortowanie, dobre obtoczenie, spoiwo porowe lub stykowe; megaskopowo sa podobne do czerwonych piaskowców dolnokredowej formacji Murco i górnej części grupy Yura.

Najczęstsze skały silikoklastyczne formacji Ashua to w klasyfikacji Pettijohna i in. (1972) mułowce i szarowaki lityczne (ryc. 2-4), natomiast rzadsze są waki arkozowe i skały hybrydowe z udziałem spoiwa węglanowego lub też gipsowego. W szkielecie ziarnowym przeważają na ogół skały wulkaniczne felsytowe, przy zmiennym udziale skaleni alkalicznych, plagioklazów i kwarcu; obecne minerały femiczne rzadko tworzą oddzielne ziarna. W facji 2 i 6 istotny udział mają klasty wapieni i kalcytowych skorup małży. 


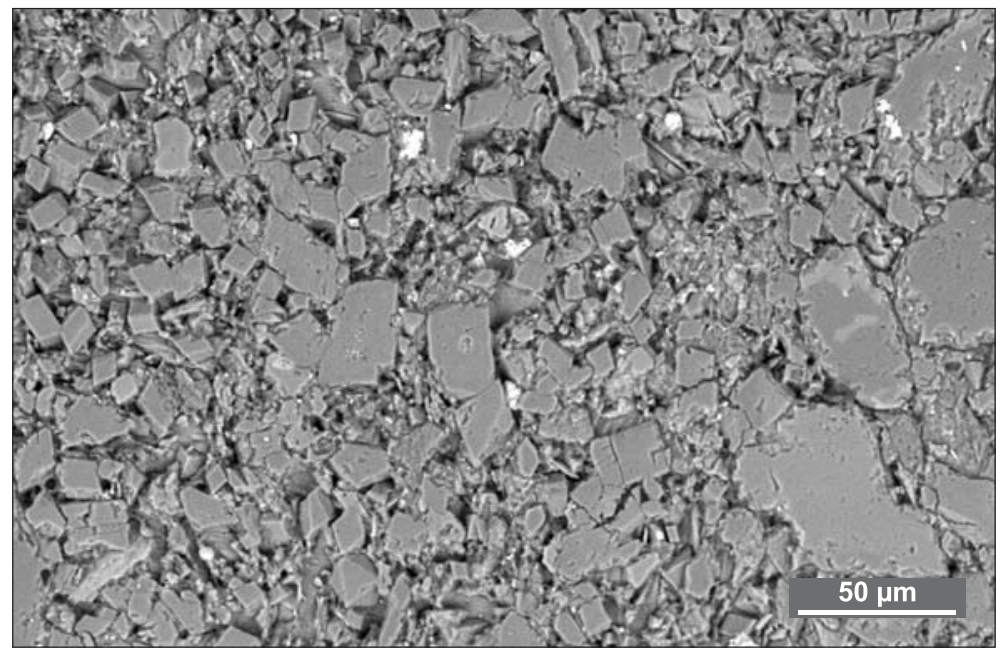

Ryc. 2. Neomorficzne romboedry dolomitu na tle masy mułowo-gipsowej. Po prawej większe klasty skały magmowej, kwarcu i plagioklazów. Sebkha

Fig. 2. Neomorphic rhomboids of dolomite versus mudstone-gypsum groundmass. To the right bigger clasts of igneous rocks, quartz and plagioclases. Sebkha

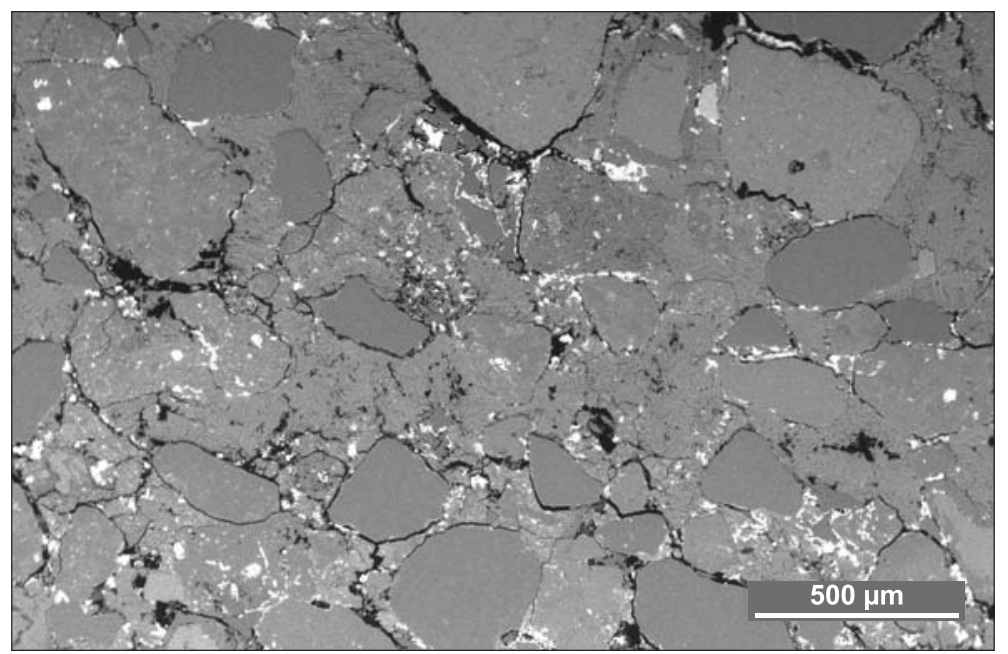

Ryc. 3. Waka arkozowa o spoiwie gipsowym: białe żyłki i mikrogniazda - baryt i celestyn. Obrzeże plai

Fig. 3. Arkose greywacke bound by gypsum: white veinlets and micronests barite and celestine. Playa rim

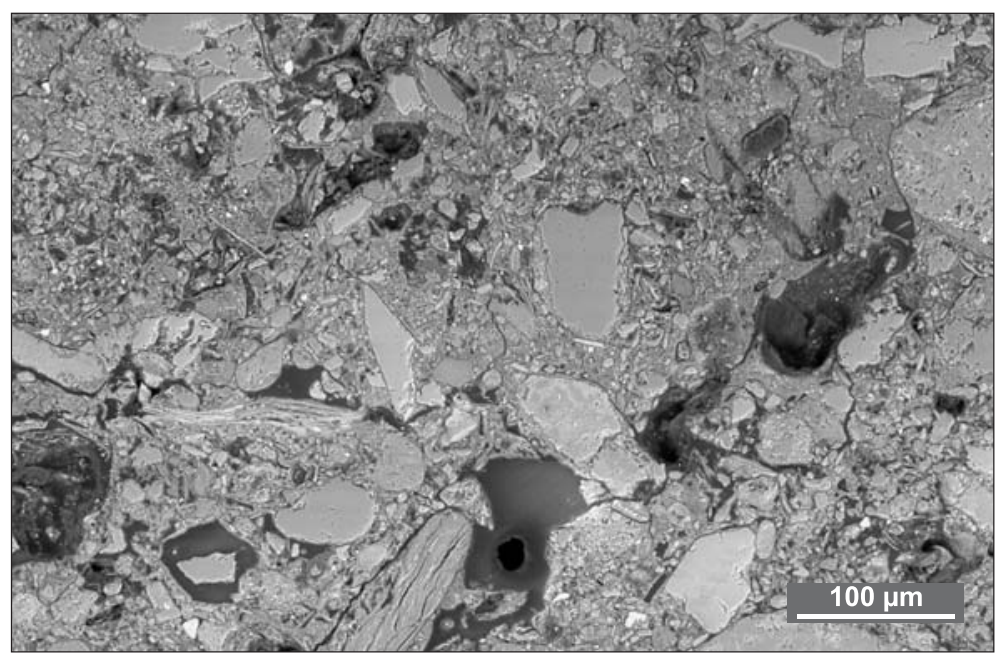

Ryc. 4. Szarogłaz. Osad potoku błotnego: czarne pola - pory skalne, ciemnoszare - pory wypełnione klejem

Fig. 4. Greywacke. Mudflow sediment: black fields - vugs in rock, dark grey vugs filled in with glue
Projekcja na trójkącie QFL (Dickinson, 1985) szkieletu ziarnowego tych skał plasuje je zazwyczaj w polu łuków magmowych - przejściowych i rozciętych. Wobec bogactwa skał magmowych i migracji łuków magmowych w czasie ewolucji Andów pożądane jest bliższe określenie, o który z nich chodzi. Jednakże brak rozeznania $\mathrm{w}$ składzie petrograficznym skał detrytycznych (poza identyfikacją kwarcu i skaleni) uniemożliwiał dotąd wskazanie źródła.

Słabe obtoczenie wskazuje na stosunkowo krótki i raczej jednorazowy transport w potokach burzowych. Źródłem były zapewne skały piroklastyczne nieodległe wiekowo od koniaku i przestrzennie od pasa Saporo-Ashua-Carumas. Formacje wulkaniczne dolnej jury i dolnej kredy w Kordylierze Nadbrzeżnej wydają się mało prawdopodobnym źródłem, gdyż formacja Ashua znana jest jedynie we wschodnim skrzydle niecki zachodniego Peru. Sugerujemy pochodzenie materiału detrytycznego $\mathrm{z}$ erozji formacji Matalaque (Cervantes i in., 2005), której wychodnie w Carumas zachowały się w odległości $20 \mathrm{~km}$ od wychodni Ashua (ryc. 1). Formacja Matalaque (apt-alb), korelowana $\mathrm{z}$ formacją Murco, rozprzestrzenioną w kierunku NW, składa się z miąższego (1100-2000 m) pakietu aglomeratów lawowych i tufów o składzie andezytowo-dacytowym oraz ignimbrytów ryolitowych (Cervantes i in., 2005). Alternatywą są deszcze piroklastyczne pochodzące $\mathrm{z}$ niezidentyfikowanego centrum eruptywnego.

Prace wykonano w ramach badań statutowych AGH nr 11.11.140.626 i UŚ nr 1S-0418-001$-1-01-01$.

\section{LITERATURA}

CALDAS J. 1993 - Geología de los cuadrangulos de Huambo y Orcopampa. INGEMMET Boletin 46, ser. A: Carta Geológica Nacional, hojas 32-r, 31-r, Lima.

CALDAS J., ROMERO D., TICONA P. 2002 - Mapa geológico del cuadrangulo de Huambo escala 1:50 000, actualizado. INGEMMET, Lima.

CERVANTES J., MARTINEZ W., ROMERO D., ZAPATA A., NAVARRO P. 2005 - The Matalaque Formation of southern Peru: New stratigraphic and geochemical data. $6^{\text {th }}$ Int. Symposium on Andean Geodynamics (ISAG 2005, Barcelona), Extended Abstracts: 162-165.

CRUZ M. 2002 - Estratigrafía y evolución tectono-sedimentaria de los depósitos sin-orogénicos del cuadrángulo de Huambo (32-r, cuadrante II): Las formaciones Ashua y Huanca. Tesis de Ingeniero Geólogo, Universidad Nacional San Agustín de Arequipa: 127.

DEMOUY S. 2012 - La naissance des Andes au Crétacé supérieur: origine et construction du Batholite Côtier sud-péruvien (Région d'Arequipa). Thèse de doctorat de l’Université de Toulouse: 321.

DICKINSON W.R. 1985 - Interpreting provenance relations from detrital modes of sandstones. NATO ASI Series, Series C: Mathematical and Physical Sciences, 148: 333-361.

MIALL A.D. 1996 - The Geology of Fluvial Deposits. Sedimentary Facies, Basin Analysis, and Petroleum Geology. Springer Verl.: 582.

PETTIJOHN F.J., POTTER P.E., SIEVER R. 1972 - Sand and sandstone. Springer Verl., New York: 618.

VICENTE J. 1981 - Cuenca sedimentaria del Jurásico y Cretácico de América del Sur. Elementos de la Estratigrafía Mesozoica Sur-Peruana. 